AEC RESEARCH AND DEVELOPMENT REPORT

AN EXPERTMENTAL STUDY OF RETINAL BURNS: PART I. THE IRRADIANCE THRESHOLDS FOR CHORIO-RETINAL IESIONS. PART II. ENTOPTIC SCATIEER AS A FUTICPION OF WAVE IENGTH

by

Doneld W. DeMott

Thames P. Devis

THE UNIVERSITY OF ROCHESTER ATOMIC ENERGY PROJECT ROCHESTER, NEW YORK 


\section{IEGAI NOTICE}

This report was prepared as an account of Government sponsored work. Nelther the United States, nor the Commission, nor any person acting on behalf of the Commission:

A. Maises any warranty or representation, expressed or implied, w1th respect to the accuracy, completeness, or usefulness of the information contained in this report, or that the use of any information, apparatus, method, or process disclosed in this report may not infringe privately owned rights; or

B. Assumes any liabilities with respect to the use of, or for damages resulting from the use of any information, apparatus, method, or process disclosed in this report.

As used in the above, "person acting on behalf of the Commission" includes ary employee or contractor of the Commission, or employee of such contractor, to the extent that such employee or contractor of the Commission, or employee of such contractor prepares, disseminates, or provides access to, any information pursuant to his employment or contract with the Commission, or his employment with such contractor. 


\section{DISCLAIMER}

This report was prepared as an account of work sponsored by an agency of the United States Government. Neither the United States Government nor any agency Thereof, nor any of their employees, makes any warranty, express or implied, or assumes any legal liability or responsibility for the accuracy, completeness, or usefulness of any information, apparatus, product, or process disclosed, or represents that its use would not infringe privately owned rights. Reference herein to any specific commercial product, process, or service by trade name, trademark, manufacturer, or otherwise does not necessarily constitute or imply its endorsement, recommendation, or favoring by the United States Government or any agency thereof. The views and opinions of authors expressed herein do not necessarily state or reflect those of the United States Government or any agency thereof. 


\section{DISCLAIMER}

Portions of this document may be illegible in electronic image products. Images are produced from the best available original document. 
U N C L A S S I F I E D

$$
\text { UR }-548
$$

Biology and Medicine TID-4500, (14th Ed。)

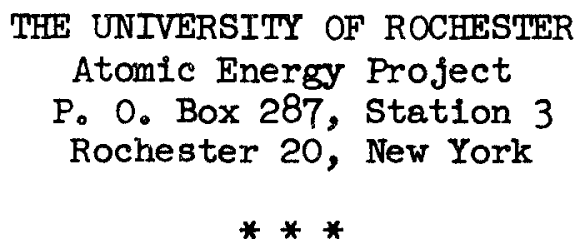

Contract W-740I-eng-49 between the U. S. Atomic Energy Commission and the University of Rochester, administered by the Department of Radiation Biology of the School of Medicine and Dentistry.

AN EXPERIMENTAL STUDY OF RETINAL BURNS: PART I。THE IRRADIANCE

THRESHOLDS FOR CHORIO-RETINAL LESIONS. PART II. ENTOPTIC

SCATTER AS A FUNCTION OF WAVE LENGTH

by

Donald W. DeMott

Thomas Po Davis

Division: Special Programs

Section: Flash Burns

Date Completed: $5 / 11 / 59$
Division Head: H. A. Blair

Section Head: J. R. Hinshaw 


\title{
AN EXPERTMENTAL STUDY OF RETTNAL BURNS: PART I. THE IRRADIANCE THRESHOLDS FOR CHORIO-RETINAL LESIONS. PART II. ENTOPTIC SCATTER AS A FUNCTION OF WAVE LENGTH
}

\begin{abstract}
Using a high intensity light source to produce chorio-retinal lesions in the eyes of rabbits, cats and guinea pigs, the authors determined, at different levels of retinal irradiance, the exposure time which produced an ophthalmoscopically visible lesion. It was found that, at irradiance levels greater than $2 \mathrm{cal} / \mathrm{cm}^{2} / \mathrm{sec}$, a radiant exposure of $1.0 \mathrm{cal} / \mathrm{cm}^{2}$ produced a threshold lesion. At irradiance levels less than $0.7 \mathrm{cal} / \mathrm{cm}^{2} / \mathrm{sec}$, lesions could not be produced at any exposure time through ten seconds. Histological data on the nature of the lesions and course of healing are presented and discussed.
\end{abstract}


AN EXPERIMENTAL STUDY OF RETINAL BURNS: PART I. THE IRRADIANCE THRESHOLDS FOR CHORIO-RETINAL LESIONS.

\section{INTRODUCTION}

Considerable information is now available concerning chorio-retinal burns produced by an atomic flash. $1,2,3,4$ The purpose of the present research was to determine the threshold conditions for the production of such lesions, and the course of healing in such a threshold burn. Since the ocular media transmit a relatively narrow spectral band, the source of energy used is not important, as long as its spectral emission covers the range from .3 to 1.3 (see Fig。 1)。 However, since species may be an important factor, and since human volunteers are not readily available, it was necessary to use several mammalian species in order to establish a basis for generalization to the human eye.

APPARATUS

The light source used in this study was a modified 5 , U.S. Army searchlight 24 inch, model 1942. The light from the carbon arc is focused by a reflector into a fairly intense beam with uniform flux-density within about $5 \mathrm{~mm}$ of the center of the beam. A graduated series of circular apertures (artificial pupils) could be placed in the center of the beam to control the intensity of retinal irradiance. Exposure time could be varied from $40 \mathrm{~m} \mathrm{sec}$ upwards by means of a shutter.

PROCEDURE

Adult, pigmented rabbits, cats and guinea pigs were used. The pupils were dilated with atropine, and the animals lightly anesthetized with

The authors wish to thank Mr. Joseph Basso for his assistance in apparatus construction and during the experimental procedure, and Miss Marilyn Aldrich for her assistance with the experimental procedure. 
Nembutal. The animal was held with its eye about $3 \mathrm{~mm}$ from the aperture, the pupil approximately centered on the beam. An exposure was made at an exposure time well below the expected threshold, and the fundus examined with an ophthalmoscope. A threshold lesion appears as a sharply translucent whitish area, apparently raised above the fundus. If no lesion was found, another exposure was made at a slightly longer exposure time, and the fundus again examined. This process was repeated until a visible lesion was produced. The threshold was taken as midway between the last two exposure times used. With the cats, it was sometimes necessary to hold the nictitating membrane out of the way with forceps, while making the exposures. There is a slight possibility that a given area of retina may have received more than one exposure. The data would then be in error if such exposures are cumulative.

CALIBRATION

The source used in the study had been previously calibrated so that the flux passing through the aperture was known. In order to obtain retinal irradiance, however, two additional factors must be known: the distribution of flux in the retinal image, and the absorption by the ocular media.

In order to determine the first of these factors, an artificial rabbit eye was constructed, consisting of an uncorrected, $12 \mathrm{~mm}$ focal length lens in a holder which permitted a piece of photographic film to be positioned in the focal plane. By using the combinations of aperture and exposure time which had produced threshold lesions in the rabbit eye, a series of photographs was obtained, having nearly identical densities. Since the exposure times were precisely known, and the reciprocity rule could be assumed over the range of exposure times used (.04 to $.8 \mathrm{sec})$, the relative irradiances from the different apertures could be readily calculated. Unfortunately, it proved impossible to obtain comparison photographs at known irradiances, so that 
absolute irradiance could not be found by this means.

By placing the artificial rabbit eye in the beam, and using a small thermistor as an energy sensing device, it was possible to obtain absolute measures of the irradiance in the "ocular" images using the different apertures. Although this method is less reliable than the photographic calibration, it was possible to use the relative scale obtained from the photographs to smooth out the irregularities in the absolute scale derived from thermistor measurements and so obtain a fairly accurate final calibration.

Since the calibration was performed with a glass lens in place of the eye, it was necessary to know the spectral transmittance of the glass and of the ocular media, in order to compute retinal irradiance from calibrated irradiance. The transmittance of the glass is readily available. The transmittance of the ocular media was measured in an excised steer eye。

The detailed procedure by which a steer eye may be prepared for such measurements has been described ${ }^{6}$ elsewhere. In brief, the eye was placed in the beam of a Perkin-Elmer Universal monochromator, and the transmitted light measured by a lead sulphide cell in an integrating sphere. The output was measured as a function of wavelength with and without the eye in the system, and the difference between the two curves used to compute transmittance. No correction was made for reflection, and the opening in the sclera through which the transmitted light was recorded was large enough to include over $90 \%$ of the scattered light, as well as the directly transmitted light. The obtained transmittance curve is shown in Fig. I. Since the eye transmits about $3 / 4$ the energy transmitted by the glass lens, the calibrated irradiance figures were multiplied by this factor to find retinal irradiance 。 
RESULTS

The threshold values for irradiance and exposure time are shown in Fig. 2. The points for the rabbit and cat eye have been plotted directly; those for the guinea pig have been corrected for the difference in focal length of the eye. The resulting curve is almost certainly a dual function. The portion of the curve to the right of $2 \mathrm{cal} / \mathrm{cm}^{2} / \mathrm{sec}$ is a straight line of slope -1, indicating that the radiant exposure necessary to produce a lesion is constant, and lies between .5 and $1.5 \mathrm{cal} / \mathrm{cm}^{2}$. To the left of this value, the curve rapidly approaches a vertical asymptote, indicating that a certain minimal level of irradiance is necessary before any exposure time will be effective. Apparently an equilibrium is established in little more than ten seconds, in which heat is being removed by the blood supply at the same rate it is being absorbed.

Since the human blink reflex occurs with a latency of about. I sec, lesions would probably not occur with a retinal irradiance less than $4 \mathrm{cal} / \mathrm{cm}^{2} / \mathrm{sec}^{\circ}$ HISTOLOGICAL DATA

The animals were sacrificed at increasing intervals, and the eyes removed for histological examination. The data consisted of sections from fourteen rabbit eyes and two guinea pig eyes, excised at periods from five minutes to thirty-six days post-burn.

No differences were found between the lesions in rabbits and guinea pigs, or as a function of the intensity of irradiance. It should be reemphasized that all lesions were near threshold.

Immediately post-trauma (5-30 minutes), the lesions consisted of intrusions of fluid, probably serum, into the sclera, choroid and retina. The most common appearance was of an intrusion between the receptor and bipolar cell layers of the retina. From 30 minutes to about four days post- 
trauma, the fluid intrusions gradually coagulated and shrank. From five to thirty-six days there is apparently a gradual resorption of the clot. At about seven days post-trauma, we find the first appearance of retinal necrosis. This is not an inevitable result of a threshold lesion, as indicated by the fact that some lesions showed no such necrosis at several weeks post-trauma, and, where the necrosis was found, it was only in the central portion of the lesion.

Assuming that the intensity of irradiance was greatest at the center of a lesion, we can establish a sequence of effects with increasing intensity. The bare minimum would appear to be an intrusion of fluid within the retina, or between the retina and choroid. The latter type of lesion produces a small, uncomplicated retinal detachment, which shows a tendency to reattach as healing progresses. Where the intrusion is between the receptor and bipolar cell layers, as is more of ten the case in these subjects, functional loss should be permanent.

A slight increase of intensity causes a destruction of retinal elements. The pigment epithelium and receptor cells are the first to be destroyed, probably because the greatest concentration of heat is in the pigment epithelium. Slightly greater intensities involve the bipolar and ganglion cell layers. Even if not directly involved, however, destruction of the receptors causes these cells to undergo a secondary degeneration, so that the final result is the same.

A near-threshold lesion, then, can take three forms: a circumscribed retinal detachment, probably temporary; a separation between the receptor and bipolar cell layers within the retina, resulting in eventual retinal degeneration; or a direct destruction of neural elements, also resulting in final degeneration. 
From these data on rabbit eyes, the authors would expect that about ninety-five percent of all threshold lesions would fall into the latter two categories, resulting in permanent visual scotomata. SUMMARY

Due to the peculiar laws of optics, the retinal irradiance from an extended source does not vary with distance, except as a function of absorption by intervening media. Aside from such absorption, retinal irradiance is a function of pupil diameter and the surface brightness of the source.

In the case of an atomic flash, the greatest probability of retinal damage would be created by a flash directly overhead, at night. Since the density of the atmosphere rapidly decreases with altitude, the filtering action of air in a vertical direction is limited, and would be insufficient to protect an observer with fully dilated pupils. In this case, an atomic flash would be expected to cause permanent visual scotomata in all observers without protective glasses. This effect would be independent of the altitude of the burst, until the visual angle subtended by the fireball became less than about 10-12 min of arc. For a nominal weapon, using data from atmospheric detonations, this limiting altitude would be of the order of 75 miles. Since this is based on the most conservative figures, the actual limiting "safe" altitude would probably be from five to ten times this figure. 
REFERENCES

1. Byrnes, V. A., Brown, D. V. L., Rose, H. W. and Cibis, P. A. Chorioretinal Burns Produced by Atomic Flash. Arch. Ophthal. 53:351 (1951).

2. Byrnes, V.A., Brown, D. V. L., Rose, H. W. and Cibis,P.A. Human Chorioretinal Burns from Atomic Fireballs. Arch. Ophthal. 55:205 (1956).

3. Ham, W. T., Jr., Weisiuger, H., Guerry, D. III, et al. Experimental Production of Flash Burns in the Rabbit Retina. Am. J. Ophth. 43:711 (1957).

4. Verhoef, F.H., Bell, L。 and Walker, C. B. The Pathological Effects of Radiant Energy on the Eye. Proc. Am.Acad. Arts and Sciences, 51:13 (1916).

5. Davis, T. P. and Pearse, H. E。 Use of Carbon Arc and Burning Magnesium as Thermal Sources for Experimental Burns. Ann. Surg. 149:68 (1959).

6. DeMott, D. W. and Boynton, R. M. Retinal Distribution of Entoptic Stray Iight. J. Opt. Soc. Amer. 48:13 (1958). 
-9-

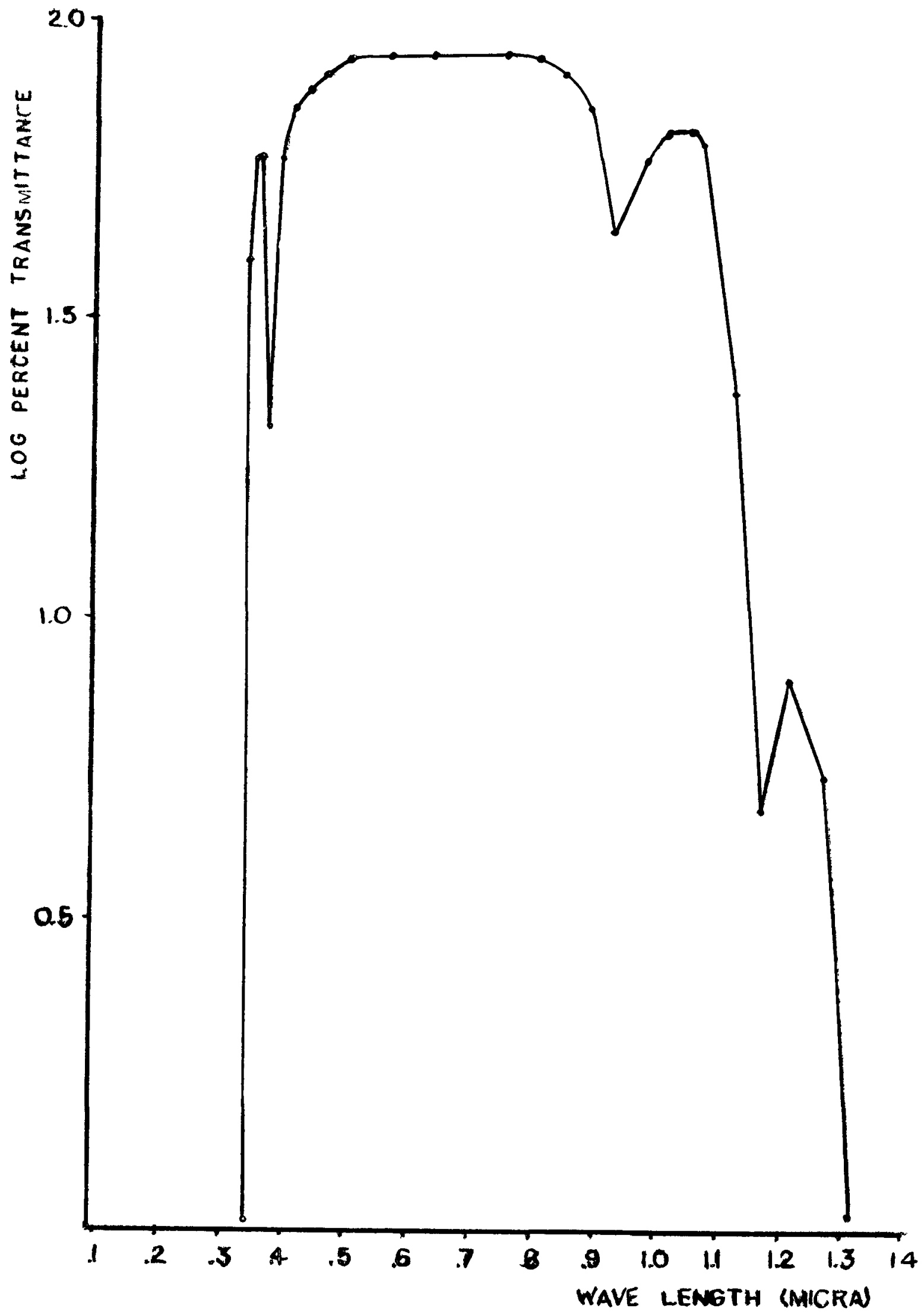

Figure 1. The spectral transmittance of the ocular media as measured in an excised steer eye, corrected for axial length to approximate the transmittance of the rabb1t (or human) eye. 


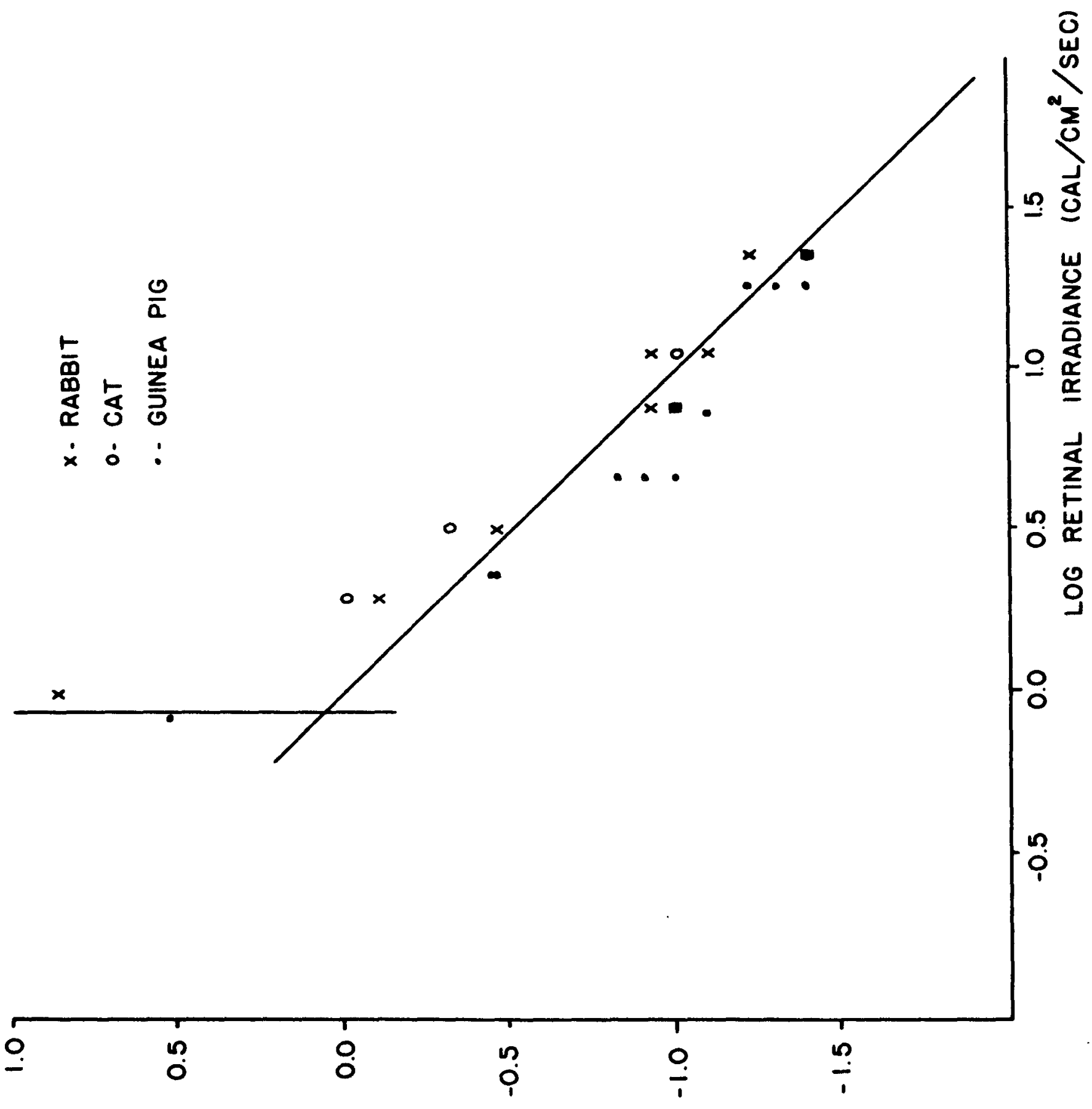

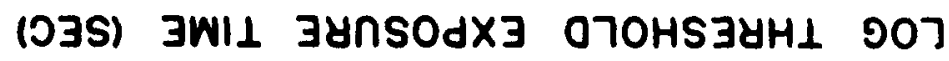

Figure 2. Exposure times required to produce a threshold retinal lesion as a function of retinal irradiance. The line of slope -1 represents a radiant exposure of $1.0 \mathrm{cal} / \mathrm{cm}^{2}$. At irradiance less than 0.7 $\mathrm{cal} / \mathrm{cm}^{2} \mathrm{sec}$, retinal lesions could not be produced at any exposure time through ten seconds. 
PART II. ENTOPTIC SCATTER AS A FUNCTION OF WAVE LENGTH

In a previously published article ${ }^{l}$, the relationship between scatter and wave length over the visible spectrum was described. The present report deals with an extension of these data into the ultraviolet and infrared. The technique for handling excised steer eyes was included in the previous article.

In the course of measuring the absorption spectrum of an excised steer eye, the authors obtained, as a by-product, a scatter function throughout the range of wavelengths transmitted by the ocular media. The technique was to measure the transmitted light through a large scleral aperture, thus including at least $90 \%$ of the scattered, as well as the directly transmitted light, and then to measure the same function, after having "stopped down" the scleral aperture to a size slightly smaller than the retinal image, thus excluding all scattered light (Fig。1)。 The difference between the two curves indicates the relative amount of scattered light as a function of wavelength. Note that this includes all scatter, and thus is not strictly comparable to the previous published data, which measured only the light scattered at an angle of about $5^{\circ}$ to the incident beam.

The results are shown in Fig. 2, where the difference between total transmitted light. (including scatter) and directly transmitted light (excluding scatter) is plotted as a function of wavelength.

Due to the sharp cut off of the ocular media, the signal-noise ratio deteriorates rapidly below $.400 \mu$. The existence of a trough and peak at .380 and $.390 \mu$ is uncertain, as is the magnitude of the peak at $.365 \mu$.

\section{REFERENCE}

1. DeMott, D. W. and Boynton, R。 H. Retinal Distribution of Entoptic Stray Light. J. Opt. Soc. Amer. $48: 13$ (1958). 


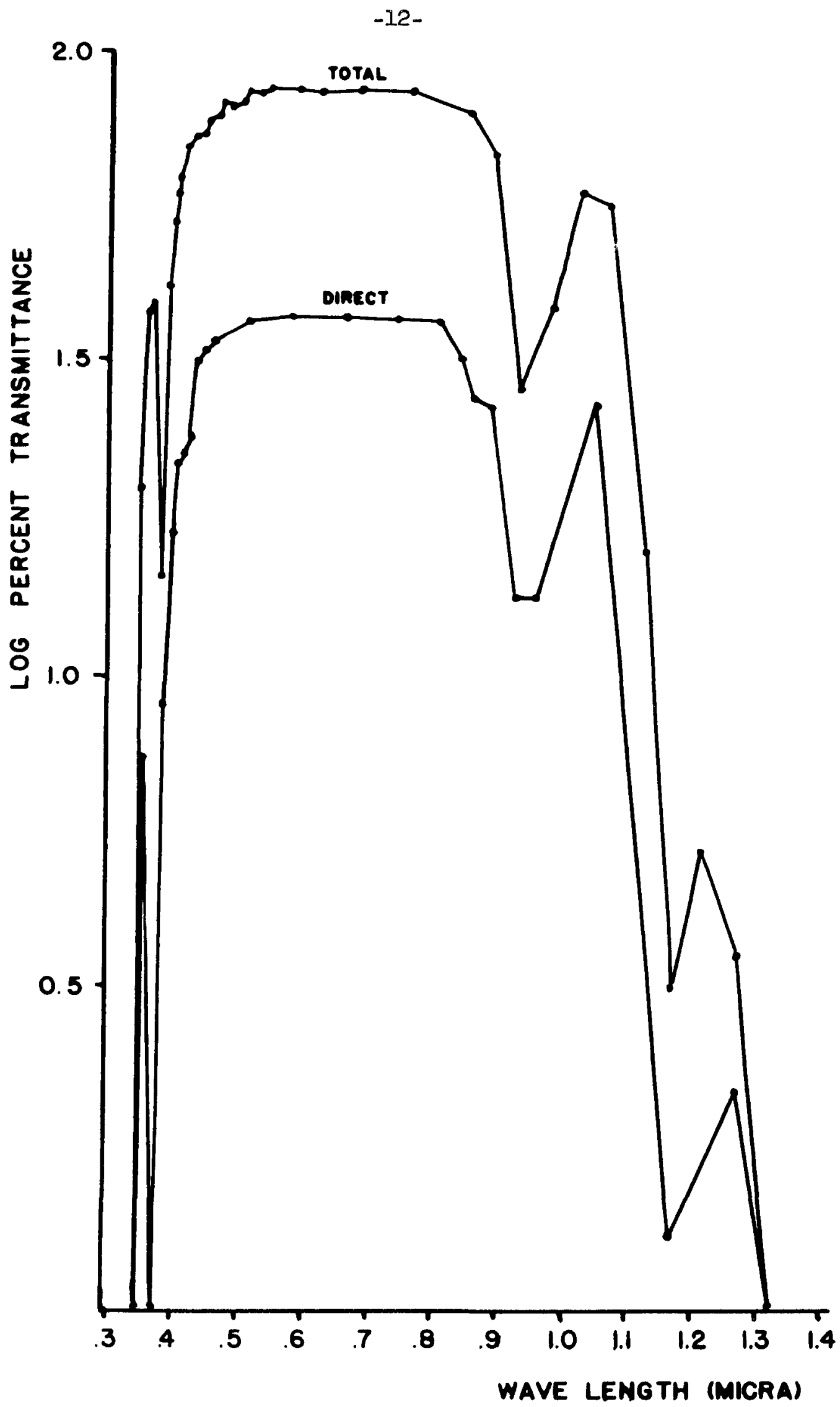

Figlire 1. Spectral transmittance of the ocular media of an excised steer eye approximately one hour after enucleation, as measured through a large scleral aperture (total) which included most of the scattered light, and through a small aperture (direct) which excluded most scattered light. 


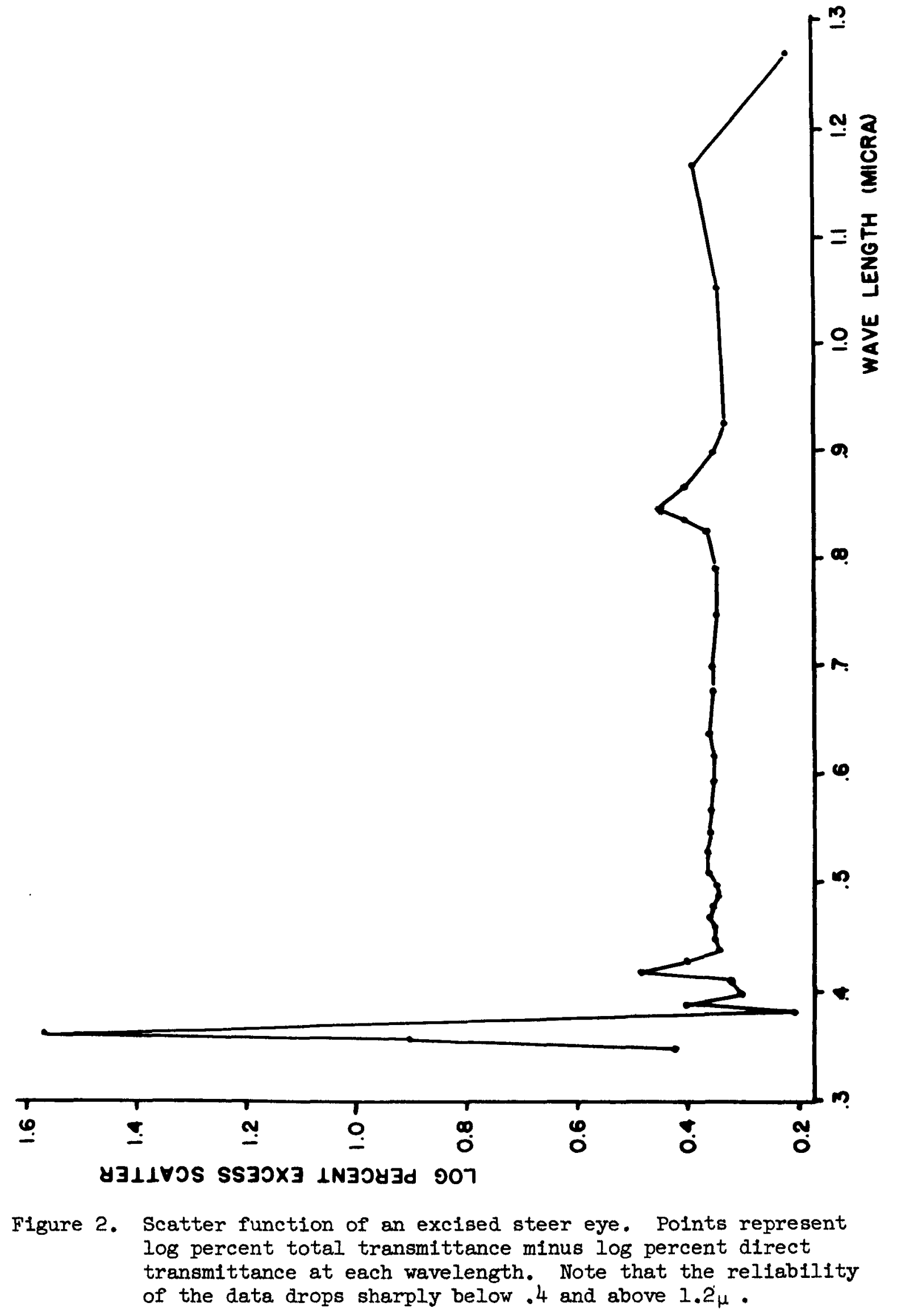

